\title{
Propensity Score Analysis Comparing Survival Between Definitive Chemoradiotherapy and Esophagectomy with Adjuvant Chemoradiotherapy in Patients with Esophageal Squamous Cell Carcinoma
}

\author{
Yi Lin Chang \\ Changhua Christian Hospital \\ Ya Fu Cheng \\ Changhua Christian Hospital \\ Hui Shan Chen \\ Chang Jung Christian University \\ Siao Chi Wu \\ National Yang Ming University \\ Wei Heng Hung \\ Changhua Christian Hospital \\ Heng Chung Chen \\ Changhua Christian Hospital

\section{Chang Lun Huang} \\ Changhua Christian Hospital \\ Ching Yuan Cheng \\ Changhua Christian Hospital \\ Bing Yen Wang ( $\nabla$ 156283@cch.org.tw) \\ Changhua Christian Hospital
}

\section{Research Article}

Keywords: esophageal cancer, esophagectomy, adjuvant chemoradiotherapy, esophageal squamous cell carcinoma

Posted Date: January 7th, 2021

DOl: https://doi.org/10.21203/rs.3.rs-130861/v1

License: @ (i) This work is licensed under a Creative Commons Attribution 4.0 International License. Read Full License 


\section{Abstract}

Background: The purpose of the current study is to compare definitive chemoradiotherapy and esophagectomy with adjuvant chemoradiotherapy in patients with cT1-3/N0-3 esophageal squamous cell carcinoma in survival.

Methods: Records from 2008 to 2014 of 4931 patients with clinical T1-3/N0-3 esophageal squamous cell carcinoma receiving definitive chemoradiotherapy or esophagectomy with adjuvant chemoradiotherapy were obtained from the Taiwan Cancer Registry. Univariable and multivariable analyses were performed and propensity score matching was used to minimize the bias. Overall survival was compared between definitive chemoradiotherapy and esophagectomy with adjuvant chemoradiotherapy, and also in the three different clinical stages.

Results: Definitive chemoradiotherapy was performed on 4381 patients, and 550 patients received esophagectomy adjuvant chemoradiotherapy. Each group produced 456 patients for comparison after propensity score matching. The 1-year, 2-year, and 3-year overall survival rates for matched patients in with definitive chemoradiotherapy group were $57.18 \%, 31.92 \%$, and $23.8 \%$. The 1-year, 2-year, and 3-year overall survival rates for matched patients treated in the esophagectomy with adjuvant chemoradiotherapy group were $72.35 \%, 45.74 \%$, and $34.04 \%(p<0.0001)$. In multivariable analysis, treatment modality was an independent prognostic factor. Esophagectomy with adjuvant chemoradiotherapy provided better survival outcome than definitive chemoradiotherapy for patients with clinical stage II/III disease. As for patients with clinical stage I disease, there was no significant survival difference between definitive chemoradiotherapy and esophagectomy with adjuvant chemoradiotherapy.

Conclusions: Esophagectomy with adjuvant chemoradiotherapy provided better survival than definitive chemoradiotherapy in clinical II/III esophageal squamous cell carcinoma. However, more data are needed to conduct a convincing conclusion in clinical stage I patients.

\section{Introduction}

Esophageal squamous cell carcinoma(ESCC) is one of the leading causes of cancer-related death. Esophageal cancer is associated with poor survival outcome because of its aggressive tumor biology, diagnosis at advanced stages, and high recurrence rate[1-3]. ESCC has high prevalence in East Asia, with Taiwan being one of the highprevalence areas.

Between 2008 and 2014, a total of 14,394 patients were newly diagnosed with ESCC in Taiwan. Most of them received definitive chemoradiotherapy(CRT)(46\%), neoadjuvant CRT with esophagectomy(13.6\%), esophagectomy alone(10.8\%), or esophagectomy with adjuvant CRT(4.8\%)[4]. Some head-to-head comparisons between these treatment strategies have been published[4-6]. Our previous studies had compared definitive CRT with neoadjuvant CRT followed by esophagectomy and definitive CRT with esophagectomy alone. Definitive CRT was suggested as a major treatment for locally advanced ESCC by the National Comprehensive Cancer Network(NCCN) guidelines, whereas adjuvant CRT is suggested for patients with positive surgical margins[7]. The role of adjuvant CRT for ESCC patients has not been investigated yet. To date, literature comparing definitive CRT and esophagectomy with adjuvant CRT is unavailable. The aim of this study was to compare the survival difference between definitive CRT and esophagectomy with adjuvant CRT, and propensity score matching was performed to minimize selection bias. 


\section{Patients And Method}

This study was designed as a retrospective study, and the number of the IRB is 171116 . The patient clinical data were retrieved from the Taiwan Cancer Registry(TCR). The TCR is a national population-based cancer database organized and funded by the Health Promotion Administration, Ministry of Health and Welfare, of the executive branch of the central government. Hospitals with more than a 50-bed capacity that provide outpatient and hospitalized cancer treatment are recruited to report all newly diagnosed malignant neoplasms to this registration database. Currently, 80 hospitals are included in this registration that accounts for more than $90 \%$ of all cancer cases in Taiwan. The TCR contains information including demographic data(i.e., sex, age, place of residence), stage at initial diagnosis(i.e., clinical and pathological stage, clinical and pathological TNM), tumor-related characteristics(date of diagnosis, primary site, tumor size, histology, grade/differentiation, modalities used for diagnosis, regional LN examined), treatment modality(date of initial treatment, date of initial surgery, surgical margins, type of chemotherapy and its schedule, starting and ending dates of radiotherapy), and follow-up information(e.g., date of recurrence, date of last contact or death).

We identified 14,394 patients in Taiwan who were diagnosed between 2008 and 2014 with ESCC. Of those patients, 6614 were treated with definitive CRT and 693 were treated with esophagectomy with adjuvant CRT. Patients received chemotherapy or radiotherapy alone were excluded from the definitive CRT group. The clinical and pathological diagnoses were staged according to 7th edition of the AJCC Cancer Staging Manual[8]. Among those 7307 patients, 5119 patients were TNM stage T1-3 and N0-3. Patients with incomplete clinical stages were excluded, and 4931 patients were finally included in this study.

Propensity score matching between definitive CRT and esophagectomy with adjuvant CRT was performed to minimize the bias resulting from nonrandomized assignment.

\section{Statistical analysis}

Categorical was compared using the chi-sqaure test and continuous variables was compared using the Student's 2-tailed t test, respectively. The Charlson score was used to adjust the bias of pre-existing comorbidities, and it is a tool for classifying clinical physical comorbidities and risk adjustment in analysis. The overall survival (OS) time was calculated from the date of initial treatment to either the date of death or December 31, 2014. To investigate the treatment effect on OS, the clinical variables: age, sex, Charlson score, clinical T, clinical N, clinical stage, histologic grade, tumor location, tumor length, and treatment modality, were included into univariable analysis and multivariable analysis before and after propensity score matching. The unmatched variables included the regimen of chemotherapy, the types of surgery(minimal invasive or not), which was not available in the definitive CRT group. The Cox proportional hazards regression model was used for univariable survival analysis and multivariable survival analysis. The OS curves were calculated by the Kaplan-Meier method, and the difference was determined by the log-rank test. Propensity scores were estimated using a logistic model that included the following variables: age, sex, Charlson score, clinical T, clinical N, clinical stage, histologic grade, tumor location, and tumor length. One-to-one propensity score matching between definitive CRT and esophagectomy with adjuvant CRT was performed to minimize the bias due to nonrandomized assignment. Each patient treated with definitive CRT was matched with one patient treated with esophagectomy with adjuvant CRT. A p-value $<0.05$ was considered statistically significant. SAS software (SAS System for Windows, version 9.3; SAS Institute, Cary, North 
Carolina) and SPSS software version 20 (IBM, Armonk, New York, USA) were used to perform the statistical analysis.

\section{Results}

A total of 4931 ESCC clinical T1-3 and N0-3 patients undergoing definitive CRT $(n=4381)$ or esophagectomy with adjuvant CRT ( $n=550)$ between 2008 and 2014 were included in this study. The clinical demographics are summarized in Table 1. The mean ages were $57.8 \pm 11.2$ in the definitive CRT group and $54.2 \pm 9.1$ years in the esophagectomy with adjuvant CRT group $(p<0.001)$. There was no significant difference in sex. Patients in the definitive CRT group were more likely to have an older age, a higher Charlson score, a higher clinical T stage, a higher clinical N stage, stage III disease, a tumor located in the upper or middle third of the esophagus, and a longer tumor length compared with patients in the esophagectomy with adjuvant CRT group. From both groups, 456 patients were selected via propensity score matching based on pre-treatment clinical and pathological variables. After propensity score matching, there was no significant difference between the groups. The wellmatched 456 patients in each group are shown in Table 1.

The 1-year, 2-year and 3-year OS rates in the definitive CRT group before matching were 46.09\%, 24.88\% and $17.87 \%$. The 1-year, 2-year and 3-year OS rates in the esophagectomy with adjuvant CRT group before matching were $74.35 \%, 47.81 \%$ and $36.02 \%$. The 1-year, 2-year and 3-year OS rates for matched patients in the definitive CRT group were $57.18 \%, 31.92 \%$ and $23.80 \%$. The 1-year, 2-year and 3-year OS rates for matched patients in the esophagectomy with adjuvant CRT group were 72.35\%, 45.74\% and 34.04\%. The 1-year, 2-year and 3-year OS rates were higher in the esophagectomy with adjuvant CRT group compared to definitive CRT group $(p<0.001)$ (Table 2).

Cox proportional hazards regression analysis identified clinical T3, clinical $\mathrm{N}+$, clinical stage, differentiated grade, tumor location, tumor length and treatment modality as significant prognostic factors before propensity score matching. After propensity score matching, clinical T3, clinical N3, clinical stage III/IV, poorly differentiated/undifferentiated, tumor length and treatment modality were significant prognostic factors(Table 3).

Charlson score, clinical T3/4, clinical stage III/IV, poorly differentiated, undifferentiated, tumor location, and tumor length were associated with worse outcomes before propensity score matching in the multivariable analysis. After propensity score matching, Charlson score(Hazard ratio:1.10, 95\% Cl:1.03-1.18, P =0.0061), clinical T3/4(HR:1.44, 95\% Cl:1.12-1.86, P = 0.0049), poorly differentiated/undifferentiated(HR:1.25, 95\% Cl:1.06-1.48, P $=0.0101)$, and tumor length(HR:1.00, 95\% Cl:1.00-1.01, P = 0.0322) were independently associated with worse outcomes, whereas the use of surgery with adjuvant CRT was an independent factor for longer survival(Table 4).

The OS curve for all ESCC patients according to the clinical stage was stratified based on treatment strategy(Fig. 1). The survival curve of all ESCC patients is shown in Fig. 1A. All ESCC patients in the surgery with adjuvant CRT group had a significant superior OS rate $(p<0.001)$. The survival curve was assessed according to the clinical stage. The OSI rate in the surgery with adjuvant CRT group was better in the definitive CRT in clinical I/II/III patients. $(p<0.05)$ (Fig. 1B, 1C and 1D).

The OS rates for matched patients are shown in Fig. 2. ESCC patients in the surgery with CRT group had a significantly better OS outcome than patients in the definitive CRT group $(p<0.001)$ (Fig. 2A). The OS curve for all matched patients according to the clinical stage was stratified based on treatment strategy (Fig. 2). Analysis of 
the propensity-matched clinical stage I patients illustrated that no significant survival difference was found between the two groups $(p=0.3185)$ (Fig. 2B). For clinical stage II and III patients, the surgery with adjuvant CRT group resulted in better OS rates than the definitive CRT group $(p<0.001)$.

\section{Discussion}

The present study investigated the OS of patients with clinical stage T1-T3, NO-N3 ESCC who were treated with definitive CRT or surgery with adjuvant CRT in Taiwan. Our results demonstrated that Charlson score, clinical T stage, tumor differentiation, tumor length and treatment modality were independent prognostic factors for OS in multivariable analysis after propensity score matching. The results also suggested surgery with adjuvant CRT had better survival than definitive CRT in clinical stage II and III ESCC patients. With regard to clinical stage I ESCC patients, no significant difference in OSI was found between the definitive CRT group and the surgery with adjuvant CRT group.

Definitive CRT is recommended as one of the definitive treatments for clinical stage T1b-T4a, N0/N+ ESCC by NCCN guidelines[7]. In Taiwan, almost $46 \%$ of ESCC patients received definitive CRT as definitive treatment between 2008 and 2014[4, 9]. The treatment efficacy of definitive CRT was established by some clinical trials, such as the RTOG 85 - 01 and RTOG 94 - 05 trials[10, 11]. Mikhail et al. reviewed 12 trials and illustrated that 2year OS of definitive chemotherapy ranged from $18-54 \%$ and 3-year OS ranged from $22.2-64.3 \%[10,12-17]$. The present study reported that 2-/3-year OS were $24.8 \% / 17.8 \%$ before matching, and $31.9 \% / 23.8 \%$ after matching. These survival outcomes were worse than the previous literature possibly because patients who received definitive CRT were diagnosed at advanced stages and were not suitable candidates for surgery. Furthermore, patient preference and hospital facilities may influence the definitive treatment modality. This might explain why definitive CRT could not provide a favorable survival outcome to patients with ESCC. As for clinical stage I ESCC patients, there were small sample size after propensity score matching.

Although surgery with adjuvant CRT was not one of the recommended treatments for locally advanced ESCC by NCCN guidelines, more than a few ESCC patients chose it as a definitive treatment in Taiwan[6,9]. For adjuvant CRT, NCCN guidelines suggested only patients with positive surgical margins should receive adjuvant CRT regardless of their nodal status[7]. However, some studies reported that adjuvant CRT could increase OS, and decrease the rates of metastasis and overall recurrence in node-positive ESCC $[18,19]$. Rice et al. demonstrated that adjuvant CRT significantly doubled survival time, time to recurrence and recurrence-free survival in patients with locoregionally advanced ESCC[20]. Hsu et al. showed that post-operative CRT was associated with longer OS, longer disease-free survival and lower locoregional recurrence[21]. However, Chen et al. illustrated that patients with resectable thoracic ESCC may not benefit from adjuvant CRT[22]. Chen et al. illustrated that 1-year and 2-year OS rates for patients with ESCC who received surgery with adjuvant CRT were $67.5 \%$ and $41.4 \%$. In the present study, 1-year and 2-year OS rates for patients with ESCC who received surgery with adjuvant CRT were $74.35 \%$ and $47.81 \%$ before matching and $72.35 \%$ and $45.74 \%$ after matching. Our results demonstrated that surgery with adjuvant CRT provided acceptable survival outcome. Usually, the side effects and toxicity of adjuvant CRT are worries for patients who undergo esophagectomy. Before the development of minimally invasive esophagectomy, patients who underwent open esophagectomy were unable to cope with any adjuvant therapy. With the advancement of minimally invasive esophagectomy, the early restoration of physical function may make patients able to endure adjuvant treatment[23]. The early recovery after minimally invasive esophagectomy may improve 
the delivery of adjuvant CRT. Thus, the role of adjuvant CRT in ESCC should be reappraised in the era of minimally invasive esophagectomy.

Neoadjuvant CRT plus esophagectomy and esophagectomy alone were main treatment strategies for clinical stage T1b-T4a, N0/N + ESCC patients in the NCCN guidelines as well. Neoadjuvant CRT plus esophagectomy is a widely acceptable treatment strategy in the world. The CROSS trial and other systematic reviews reported the treatment efficacy of neoadjuvant CRT plus esophagectomy[24, 25]. However, some clinical trials were unable to find out the role of esophagectomy when added to CRT[26, 27]. As for esophagectomy alone, multiple studies were conducted to compare surgery alone with definitive CRT[28-30]. These studies concluded that no statistically significant difference in OS between surgery alone and definitive CRT was seen. Therefore, further head-to-head comparison studies are needed to conclude the advantages and disadvantages of each treatment strategy.

In Taiwan, 14,394 patients were newly diagnosed with ESCC between 2008 and 2014. Most of them received definitive CRT, CRT plus esophagectomy, esophagectomy alone, or esophagectomy plus adjuvant CRT[4, 9]. In order to find out which treatment strategy could provide the best treatment outcome for patients with locally advanced ESCC, head-to-head comparisons between each treatment strategy were necessary. Wang et al. had compared definitive CRT with neoadjuvant CRT plus esophagectomy, and definitive CRT with esophagectomy alone[4, 6]. Until today, there was no literature comparing definitive CRT and esophagectomy plus adjuvant CRT. This is the first study to directly compare definitive CRT and esophagectomy plus adjuvant CRT using a large number of cases and propensity score matching to reduce the selection bias.

The Taiwan Cancer Registry database is a multi-center and population-based database. It has limitations that are inherent to all cohort studies because it is a retrospectivelyprospectively maintained database. First of all, the definitive CRT group were tended to be at advanced stage in the present study. Therefore, propensity score matching was performed to minimize selection bias. There are still some confounding factors that we cannot overcome. First, there is no information about the performance status before surgery and CRT. Second, the regimen of chemotherapy and the dosage and field of radiotherapy were not disclosed in the present study. Third, details about surgical procedures, postoperative complications and recurrence were lacking in this database. Fourth, the TCR database didn't include the information about how many of these ESCC patients were planned to treat with esophagectomy and adjuvant CRT from the initial diagnosis and staging. Due to the retrospective nature of our study, a randomized control trial to validate results is necessary.

\section{Conclusion}

This propensity-matched study demonstrated that esophagectomy with adjuvant CRT had better survival than definitive CRT in clinical stage II/III ESCC. As for clinical stage I ESCC patients, more data are needed to conduct a convincing conclusion.

\section{Abbreviations}

CRT

chemoradiotherapy

ESCC

esophageal squamous cell carcinoma 
TCR

Taiwan Cancer Registry

NCCN

National Comprehensive Cancer Network

OS

overall survival

\section{Declarations}

Ethics approval and consent to participate: This study was approved by the Institutional Review Board of Changhua Christian Hospital, Taiwan. The IRB number is 171116 . All the study methods were in accordance with the Declaration of Helsinki. Written informed consent was not applicable due to the data of this study was retrieved from the Taiwan Cancer Registry database.

Consent for publication: Not applicable.

Availability of data and materials: The data that support the findings of this study are available from the Taiwan Cancer Registry database but restrictions apply to the availability of these data, which were used under license for the current study, and so are not publicly available. Data are however available from the authors upon reasonable request and with permission of the Taiwan Cancer Registry database.

Competing interests: The authors have no any competing interest to declare.

Funding: This study is not funded by any institution or company.

Authors' contributions: Yi-Lin Chang: Writing-original draft; Writing-review \& editing. Ya-Fu Cheng: Writing-review \& editing. Hui-Shan Chen: Software; Visualization. Siao-Chi Wu: Software; Visualization. Wei-Heng Hung: Validation; Resources. Heng-Chung Chen: Validation; Resources. Chang-Lun Huang: Validation; Resources. Ching-Yuan Cheng: Validation; Resources. Bing-Yen Wang: Conceptualization; Data curation; Investigation; Methodology; Supervision.

\section{References}

1. Chen MF, Yang YH, Lai CH, Chen PC, Chen WC: Outcome of patients with esophageal cancer: a nationwide analysis. Ann Surg Oncol 2013, 20(9):3023-3030.

2. $<$ [15401413 - Journal of the National Comprehensive Cancer Network] Comparison of Pathologic Stage in Patients Receiving Esophagectomy With and Without Preoperative Chemoradiation Therapy for Esophageal SCC.pdf>.

3. Chen HS, Hung WH, Ko JL, Hsu PK, Liu CC, Wu SC, Lin CH, Wang BY: Impact of Treatment Modalities on Survival of Patients With Locoregional Esophageal Squamous-Cell Carcinoma in Taiwan. Medicine (Baltimore) 2016, 95(10):e3018.

4. Wang B-Y, Wu S-C, Chen H-C, Hung W-H, Lin C-H, Huang C-L, Chen H-S: Survival after neoadjuvant chemoradiotherapy and oesophagectomy versus definitive chemoradiotherapy for patients with oesophageal squamous cell carcinoma. 2019, 106(3):255-262. 
5. Hwang JY, Chen HS, Hsu PK, Chao YK, Wang BY, Huang CS, Liu CC, Wu SC: A Propensity-matched Analysis Comparing Survival After Esophagectomy Followed by Adjuvant Chemoradiation to Surgery Alone for Esophageal Squamous Cell Carcinoma. Ann Surg 2016, 264(1):100-106.

6. Wang BY, Hung WH, Wu SC, Chen HC, Huang CL, Lin CH, Chen HS: Comparison Between Esophagectomy and Definitive Chemoradiotherapy in Patients With Esophageal Cancer. Ann Thorac Surg 2019, 107(4):10601067.

7. $<[15401413$ - Journal of the National Comprehensive Cancer Network] Esophageal and Esophagogastric Junction Cancers, Version 1.2015.pdf>.

8. Rice TW, Blackstone EH, Rusch VWJAoSO: 7th Edition of the AJCC Cancer Staging Manual: Esophagus and Esophagogastric Junction. 2010, 17(7):1721-1724.

9. Cheng YF, Chen HS, Wu SC, Chen HC, Hung WH, Lin CH, Wang BY: Esophageal squamous cell carcinoma and prognosis in Taiwan. Cancer Med 2018, 7(9):4193-4201.

10. Cooper JS, Guo MD, Herskovic A, Macdonald JS, Martenson J, James A., Al-Sarraf M, Byhardt R, Russell AH, Beitler JJ, Spencer S et al: Chemoradiotherapy of Locally Advanced Esophageal CancerLong-term Follow-up of a Prospective Randomized Trial (RTOG 85 - 01). JAMA 1999, 281(17):1623-1627.

11. Minsky BD, Pajak TF, Ginsberg RJ, Pisansky TM, Martenson J, Komaki R, Okawara G, Rosenthal SA, Kelsen DP: INT 0123 (Radiation Therapy Oncology Group 94 - 05) Phase III Trial of Combined-Modality Therapy for Esophageal Cancer: High-Dose Versus Standard-Dose Radiation Therapy. 2002, 20(5):1167-1174.

12. Crosby T, Hurt CN, Falk S, Gollins S, Staffurth J, Ray R, Bridgewater JA, Geh JI, Cunningham D, Blazeby J et al: Long-term results and recurrence patterns from SCOPE-1: a phase II/III randomised trial of definitive chemoradiotherapy +/- cetuximab in oesophageal cancer. British journal of cancer 2017, 116(6):709-716.

13. Zhu H-T, Ai D-S, Tang H-R, Badakhshi H, Fan J-H, Deng J-Y, Zhang J-H, Chen Y, Zhang Z, Xia Y et al: Long-term results of paclitaxel plus cisplatin with concurrent radiotherapy for loco-regional esophageal squamous cell carcinoma. World Journal of Gastroenterology 2017, 23(3).

14. Song T, Zhang X, Fang M, Zhao R, Wu S: Long-term results of definitive concurrent chemoradiotherapy using paclitaxel plus oxaliplatin in unresectable locally advanced esophageal cancer: a prospective phase II trial. 2016, 5(12):3371-3377.

15. Servagi-Vernat S, Créhange G, Roullet B, Guimas V, Maingon P, Puyraveau M, Bosset JFJD, Aging: Phase II Study of a Platinum-Based Adapted Chemotherapy Regimen Combined with Radiotherapy in Patients 75 Years and Older with Esophageal Cancer. 2015, 32(6):487-493.

16. Xia Y, Li Y-h, Chen Y, Liu Q, Zhang J-h, Deng J-y, Ai T-s, Zhu H-t, Badakhshi H, Zhao K-LJIJoCO: A phase II trial of concurrent chemoradiotherapy with weekly paclitaxel and carboplatin in advanced oesophageal carcinoma. 2018, 23(3):458-465.

17. Mikhail S, Wei L, Salem ME, Bekaii-Saab T: Outcomes of definitive chemoradiation in patients with esophageal cancer. Diseases of the Esophagus 2017, 30(2):1-7.

18. Wang ZW, Luan ZP, Zhang W, Dong W, Fu CR, Wang YN, Li BS: Postoperative chemoradiotherapy improves survival in esophageal squamous cell cancer with extracapsular lymph node extension. Neoplasma 2014, 61(06):732-738.

19. Bedard EL, Inculet RI, Malthaner RA, Brecevic E, Vincent M, Dar R: The role of surgery and postoperative chemoradiation therapy in patients with lymph node positive esophageal carcinoma. Cancer2001, 91(12):2423-2430. 
20. Rice TW, Adelstein DJ, Chidel MA, Rybicki LA, DeCamp MM, Murthy SC, Blackstone EH: Benefit of postoperative adjuvant chemoradiotherapy in locoregionally advanced esophageal carcinoma. The Journal of Thoracic and Cardiovascular Surgery 2003, 126(5):1590-1596.

21. Hsu PK, Chen HS, Huang CS, Liu CC, Hsieh CC, Hsu HS, Wu YC, Wu SC: Patterns of recurrence after oesophagectomy and postoperative chemoradiotherapyversussurgery alone for oesophageal squamous cell carcinoma. British Journal of Surgery 2017, 104(1):90-97.

22. Chen H, Wu Z, Chen J, Lin X, Zheng C, Fan Y, Zhang Z, Yao X, Wu J, Xu L et al: Postoperative adjuvant therapy for resectable thoracic esophageal squamous cell carcinoma: a retrospective analysis of 426 cases. Med Oncol 2015, 32(1):417.

23. Outcomes, quality of life, and survival after esophagectomy for squamous cell carcinoma:A propensity score-matched comparison of operative approaches. The Journal of Thoracic and Cardiovascular Surgery 2015, 149(4):1006-1015.e1004.

24. van Hagen P, Hulshof MCCM, van Lanschot JJB, Steyerberg EW, Henegouwen MIvB, Wijnhoven BPL, Richel DJ, Nieuwenhuijzen GAP, Hospers GAP, Bonenkamp JJ et al: Preoperative Chemoradiotherapy for Esophageal or Junctional Cancer. 2012, 366(22):2074-2084.

25. Sjoquist KM, Burmeister BH, Smithers BM, Zalcberg JR, Simes RJ, Barbour A, Gebski V: Survival after neoadjuvant chemotherapy or chemoradiotherapy for resectable oesophageal carcinoma: an updated metaanalysis. The Lancet Oncology 2011, 12(7):681-692.

26. Stahl M, Stuschke M, Lehmann N, Meyer H-J, Walz MK, Seeber S, Klump B, Budach W, Teichmann R, Schmitt $\mathrm{M}$ et al: Chemoradiation With and Without Surgery in Patients With Locally Advanced Squamous Cell Carcinoma of the Esophagus. 2005, 23(10):2310-2317.

27. Bedenne L, Michel P, Bouché O, Milan C, Mariette C, Conroy T, Pezet D, Roullet B, Seitz J-F, Herr J-P et al: Chemoradiation Followed by Surgery Compared With Chemoradiation Alone in Squamous Cancer of the Esophagus: FFCD 9102. 2007, 25(10):1160-1168.

28. Carstens H, Albertsson M, Friesland S, Adell G, Frykholm G, Wagenius G, Myrvold HE, Farago I, Stockeld D: A randomized trial of chemoradiotherapy versus surgery alone in patients with resectable esophageal cancer. 2007, 25(18_suppl):4530-4530.

29. Teoh AYB, Chiu PWY, Yeung WK, Liu SYW, Wong SKH, Ng EKW: Long-term survival outcomes after definitive chemoradiation versus surgery in patients with resectable squamous carcinoma of the esophagus: results from a randomized controlled trial. Annals of Oncology 2012, 24(1):165-171.

30. Karran A, Blake P, Chan D, Reid TD, Davies IL, Kelly M, Roberts SA, Crosby T, Lewis WG: Propensity score analysis of oesophageal cancer treatment with surgery or definitive chemoradiotherapy. 2014, 101(5):502510.

\section{Tables}


Table 1

Clinical demographic data of all ESCC patients treated via definitive CRT or esophagectomy with adjuvant CRT

\begin{tabular}{|c|c|c|c|c|c|c|c|c|c|c|}
\hline \multirow{4}{*}{ Characteristics } & \multicolumn{5}{|c|}{ All Patients } & \multicolumn{5}{|c|}{ Propensity-Matched Patients } \\
\hline & \multirow{2}{*}{\multicolumn{2}{|c|}{$\begin{array}{l}\text { CCRT } \\
(n=4,381)\end{array}$}} & \multirow{2}{*}{\multicolumn{2}{|c|}{$\begin{array}{l}\text { Surgery with } \\
\text { adjuvant } \\
\text { therapy } \\
(n=550)\end{array}$}} & \multirow[t]{3}{*}{$\begin{array}{l}\mathrm{p}- \\
\text { value }\end{array}$} & \multirow{2}{*}{\multicolumn{2}{|c|}{$\begin{array}{l}\text { CCRT } \\
(n=456)\end{array}$}} & \multirow{2}{*}{\multicolumn{2}{|c|}{$\begin{array}{l}\text { Surgery with } \\
\text { adjuvant } \\
\text { therapy } \\
(n=456)\end{array}$}} & \multirow[t]{3}{*}{$\begin{array}{l}\mathrm{p}- \\
\text { value }\end{array}$} \\
\hline & & & & & & & & & & \\
\hline & $\mathrm{N}$ & $\%$ & $\mathrm{~N}$ & $\%$ & & $\mathrm{~N}$ & $\%$ & $\mathrm{~N}$ & $\%$ & \\
\hline \multicolumn{11}{|l|}{ Age (year) } \\
\hline Mean \pm SD & \multicolumn{2}{|c|}{$57.8 \pm 11.2$} & \multicolumn{2}{|c|}{$54.2 \pm 9.1$} & $<0.001$ & \multicolumn{2}{|l|}{$55.3 \pm 11.3$} & \multicolumn{2}{|c|}{$54.9 \pm 9.1$} & 0.5736 \\
\hline Sex & & & & & 0.4660 & & & & & 0.8832 \\
\hline Male & 4,173 & 95.25 & 520 & 94.55 & & 431 & 94.52 & 432 & 94.74 & \\
\hline Female & 208 & 4.75 & 30 & 5.45 & & 25 & 5.48 & 24 & 5.26 & \\
\hline Charlson score & \multicolumn{2}{|c|}{$0.8 \pm 1.3$} & \multicolumn{2}{|c|}{$0.5 \pm 0.9$} & $<0.001$ & \multicolumn{2}{|l|}{$0.7 \pm 1.2$} & \multicolumn{2}{|c|}{$0.6 \pm 1.0$} & 0.0619 \\
\hline Clinical T & & & & & $<0.001$ & & & & & 0.4134 \\
\hline $1 / 2$ & 1,047 & 23.90 & 216 & 39.27 & & 180 & 39.47 & 168 & 36.84 & \\
\hline 3 & 3,334 & 76.10 & 334 & 60.73 & & 276 & 60.53 & 288 & 63.16 & \\
\hline Clinical N & & & & & $<0.001$ & & & & & 0.7296 \\
\hline 0 & 741 & 16.91 & 218 & 39.64 & & 168 & 36.84 & 161 & 35.31 & \\
\hline 1 & 1,843 & 42.07 & 269 & 48.91 & & 233 & 51.10 & 235 & 51.54 & \\
\hline 2 & 1,090 & 24.88 & 54 & 9.82 & & 44 & 9.65 & 52 & 11.40 & \\
\hline 3 & 707 & 16.14 & 9 & 1.64 & & 11 & 2.41 & 8 & 1.75 & \\
\hline Clinical stage & & & & & $<0.001$ & & & & & 0.8599 \\
\hline 1 & 169 & 3.86 & 43 & 7.82 & & 35 & 7.68 & 33 & 7.24 & \\
\hline II & 769 & 17.55 & 247 & 44.91 & & 196 & 42.98 & 185 & 40.57 & \\
\hline III & 2,192 & 50.03 & 235 & 42.73 & & 204 & 44.74 & 215 & 47.15 & \\
\hline
\end{tabular}


Table 2

Overall survival rate of all ESCC patients treated via definitive CRT or esophagectomy with adjuvant CRT

\begin{tabular}{|c|c|c|c|c|c|c|}
\hline \multirow[t]{2}{*}{ Timing } & \multicolumn{3}{|c|}{ All Patients } & \multicolumn{3}{|c|}{ Propensity-Matched Patients } \\
\hline & $\begin{array}{l}\text { CRT } \\
(n= \\
4,381)\end{array}$ & $\begin{array}{l}\text { Surgery with adjuvant } \\
\text { CRT } \\
(n=550)\end{array}$ & $\begin{array}{l}\mathrm{p}- \\
\text { value }\end{array}$ & $\begin{array}{l}\text { CRT } \\
(n= \\
456)\end{array}$ & $\begin{array}{l}\text { Surgery with adjuvant } \\
\text { CRT } \\
(n=456)\end{array}$ & $\begin{array}{l}\mathrm{p}- \\
\text { value }\end{array}$ \\
\hline One year & $46.09 \%$ & $74.35 \%$ & $\begin{array}{l}< \\
0.001\end{array}$ & $57.18 \%$ & $72.35 \%$ & $\begin{array}{l}<.001 \\
0.00\end{array}$ \\
\hline Two year & $24.88 \%$ & $47.81 \%$ & $\begin{array}{l}<.001 \\
0\end{array}$ & $31.92 \%$ & $45.74 \%$ & $\begin{array}{l}<.001 \\
0.00\end{array}$ \\
\hline $\begin{array}{l}\text { Three } \\
\text { year }\end{array}$ & $17.87 \%$ & $36.02 \%$ & $\begin{array}{l}< \\
0.001\end{array}$ & $23.80 \%$ & $34.04 \%$ & $\begin{array}{l}< \\
0.001\end{array}$ \\
\hline
\end{tabular}


Table 3

Univariable analysis for all patients before and after propensity matching

\begin{tabular}{|c|c|c|c|c|c|c|}
\hline \multirow[t]{2}{*}{ Characteristics } & \multicolumn{3}{|c|}{ All Patients } & \multicolumn{3}{|c|}{ Propensity-Matched Patients } \\
\hline & HR & $95 \% \mathrm{Cl}$ & p-value & HR & $95 \% \mathrm{Cl}$ & p-value \\
\hline Age (year) & 1.00 & $\begin{array}{l}1.00- \\
1.00\end{array}$ & 0.3120 & 1.00 & $1.00-1.01$ & 0.5847 \\
\hline \multicolumn{7}{|l|}{ Sex } \\
\hline Male & 1 & & & 1 & & \\
\hline Female & 0.77 & $\begin{array}{l}0.66- \\
0.90\end{array}$ & 0.0007 & 0.82 & $\begin{array}{l}0.57- \\
1.17\end{array}$ & 0.2708 \\
\hline Charlson socre & 1.01 & $\begin{array}{l}0.98- \\
1.04\end{array}$ & 0.4718 & 1.07 & $1.00-1.14$ & 0.0623 \\
\hline \multicolumn{7}{|l|}{ Clinical T } \\
\hline $1 / 2$ & 1 & & & 1 & & \\
\hline 3 & 1.61 & $\begin{array}{l}1.49- \\
1.74\end{array}$ & $<0.001$ & 1.60 & $\begin{array}{l}1.36- \\
1.89\end{array}$ & $<0.001$ \\
\hline \multicolumn{7}{|l|}{ Clinical N } \\
\hline 0 & 1 & & & 1 & & \\
\hline 1 & 1.45 & $\begin{array}{l}1.33- \\
1.59\end{array}$ & $<0.001$ & 1.18 & $1.00-1.39$ & 0.0564 \\
\hline 2 & 1.63 & $\begin{array}{l}1.47- \\
1.80\end{array}$ & $<0.001$ & 1.04 & $\begin{array}{l}0.79- \\
1.38\end{array}$ & 0.7692 \\
\hline 3 & 2.21 & $\begin{array}{l}1.98- \\
2.46\end{array}$ & $<0.001$ & 1.77 & $\begin{array}{l}1.05- \\
2.98\end{array}$ & 0.0331 \\
\hline \multicolumn{7}{|l|}{ Clinical stage } \\
\hline I & 1 & & & 1 & & \\
\hline II & 1.29 & $\begin{array}{l}1.07- \\
1.56\end{array}$ & 0.0090 & 1.38 & $\begin{array}{l}0.98- \\
1.93\end{array}$ & 0.0637 \\
\hline III & 1.98 & $\begin{array}{l}1.65- \\
2.37\end{array}$ & $<0.001$ & 1.75 & $\begin{array}{l}1.26- \\
2.45\end{array}$ & 0.0009 \\
\hline IV & 3.19 & $\begin{array}{l}2.65- \\
3.83\end{array}$ & $<0.001$ & 2.73 & $\begin{array}{l}1.74- \\
4.27\end{array}$ & $<0.001$ \\
\hline \multicolumn{7}{|l|}{ Grade } \\
\hline $\begin{array}{l}\text { Well differentiated/ Moderately } \\
\text { differentiated }\end{array}$ & 1 & & & 1 & & \\
\hline Poorly differentiated / Undifferentiated & 1.11 & $\begin{array}{l}1.03- \\
1.21\end{array}$ & 0.0078 & 1.23 & $\begin{array}{l}1.04- \\
1.45\end{array}$ & 0.0132 \\
\hline
\end{tabular}




\begin{tabular}{|c|c|c|c|c|c|c|}
\hline \multirow[t]{2}{*}{ Characteristics } & \multicolumn{3}{|c|}{ All Patients } & \multicolumn{3}{|c|}{ Propensity-Matched Patients } \\
\hline & HR & $95 \% \mathrm{Cl}$ & p-value & HR & $95 \% \mathrm{Cl}$ & p-value \\
\hline Unknown & 1.17 & $\begin{array}{l}1.08- \\
1.25\end{array}$ & $<0.001$ & 0.89 & $\begin{array}{l}0.50- \\
1.58\end{array}$ & 0.6936 \\
\hline \multicolumn{7}{|l|}{ Tumor location } \\
\hline Upper & 1 & & & 1 & & \\
\hline Lower & 1.15 & $\begin{array}{l}1.04- \\
1.26\end{array}$ & 0.0050 & 1.19 & $\begin{array}{l}0.88- \\
1.60\end{array}$ & 0.2600 \\
\hline Middle & 1.13 & $\begin{array}{l}1.04- \\
1.24\end{array}$ & 0.0057 & 1.13 & $\begin{array}{l}0.85- \\
1.52\end{array}$ & 0.4038 \\
\hline Tumor length & 1.01 & $\begin{array}{l}1.01- \\
1.01\end{array}$ & $<0.001$ & 1.01 & $1.00-1.01$ & $<0.001$ \\
\hline \multicolumn{7}{|l|}{ Treatment modality } \\
\hline CRT & 1 & & & 1 & & \\
\hline Surgery with adjuvant CRT & 0.53 & $\begin{array}{l}0.47- \\
0.59\end{array}$ & $<0.001$ & 0.69 & $\begin{array}{l}0.59- \\
0.80\end{array}$ & $<0.001$ \\
\hline
\end{tabular}


Table 4

Multivariable analysis for all patients before and after propensity matching

\section{All Patients}

AHR $\quad 95 \% \mathrm{Cl}$

$1.00 \quad 1.00-1.00$ p-value

0.4780

\section{Propensity-Matched Patients}

AHR $95 \% \mathrm{Cl} \quad$ p-value

$1.00 \quad 0.99-1.01$

Sex

Male

1

1

Female

0.81

$0.67-0.98$

0.0260

0.86

$0.60-1.23$

0.4120

Charlson score

$1.05 \quad 1.02-1.08$

0.0038

1.10

1.03-1.18

0.0061

Clinical T

$1 / 2$

1

$1.21 \quad 1.08-1.36$

0.0014

1.44

$1.12-1.86$

0.0049

Clinical N

0

1

1

2

3

1

0.90

0.76-1.07

0.2314

0.91

$0.69-1.22$

0.5293

$0.97 \quad 0.80-1.18$

0.7729

0.80

$0.53-1.21$

0.2876

$1.14 \quad 0.93-1.40$

0.2053

1.33

$0.73-2.43$

0.3553

Clinical stage

II

III

IV

Grade

Well differentiated/ Moderately differentiated

Poorly differentiated /

Undifferentiated

Unknown

1.04

$0.95-1.15$

0.3644

0.1981

1.22

$0.84-1.77$

0.2933

$1.48 \quad 1.07-2.05$

0.0173

1.32

$0.76-2.30$

0.3230

2.18

$1.59-3.00$

$<0.001$

2.41

$1.36-4.28$

0.0027

Tumor location

Upper

1

Lower

1.26

$1.12-1.42$

0.0002

1.20

$0.88-1.63$

0.2551

Middle

1.23

$1.10-1.37$

0.0003

1.29

$0.95-1.74$

0.1003

Unknown

$1.00-1.28$

0.0437

1.23

$0.91-1.68$

0.1843 


\begin{tabular}{|c|c|c|c|c|c|c|}
\hline \multirow[b]{2}{*}{ Tumor length } & \multicolumn{3}{|c|}{ All Patients } & \multicolumn{3}{|c|}{ Propensity-Matched Patients } \\
\hline & 1.00 & $1.00-1.01$ & $<0.001$ & 1.00 & $1.00-1.01$ & 0.0322 \\
\hline \multicolumn{7}{|l|}{ Treatment modality } \\
\hline CRT & 1 & & & 1 & & \\
\hline Surgery with adjuvant CRT & 0.65 & $0.57-0.74$ & $<0.001$ & 0.66 & $0.56-0.77$ & $<0.001$ \\
\hline
\end{tabular}

\section{Figures}
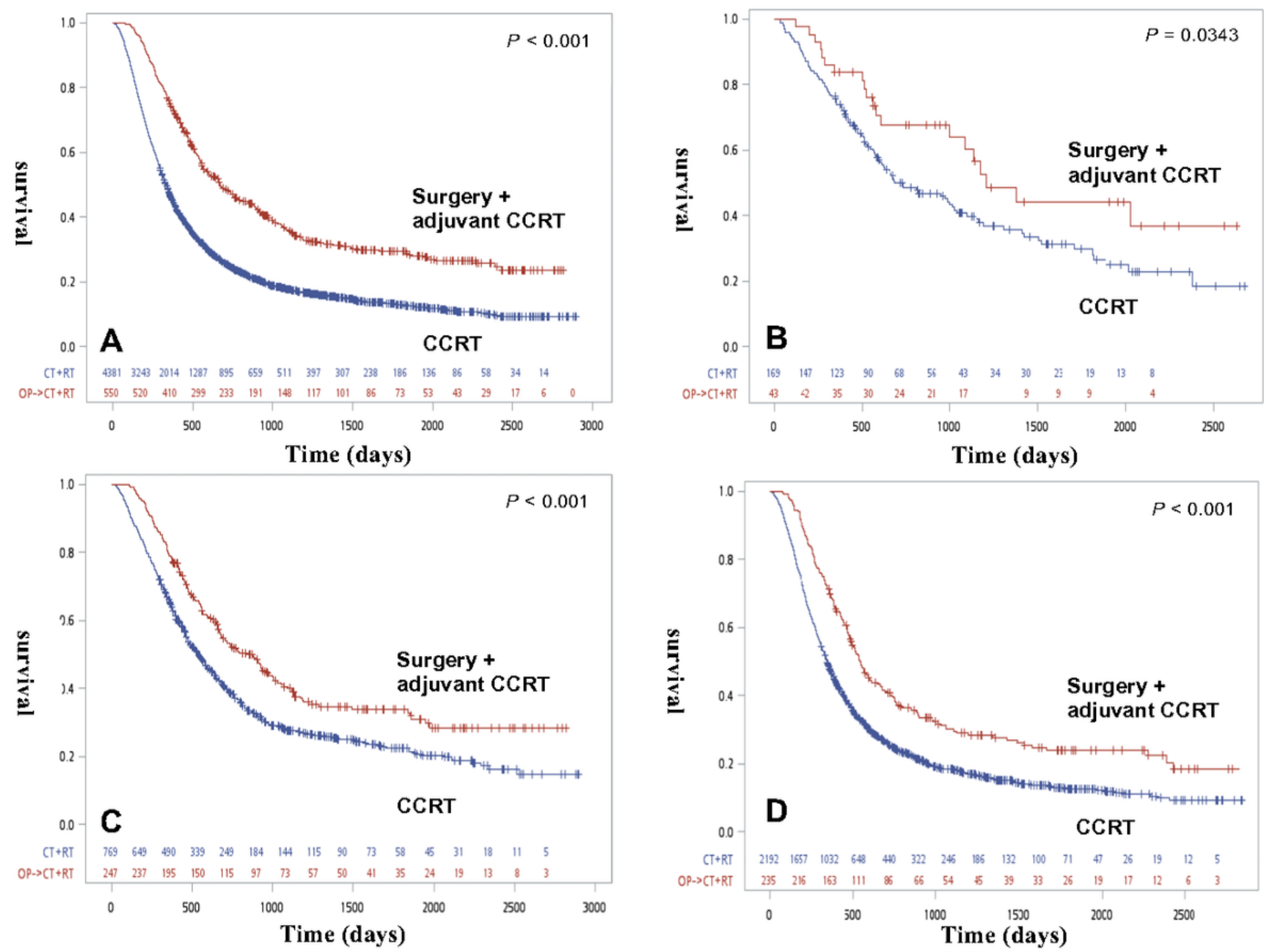

Figure 1

(A) Kaplan-Meier survival curves for ALL ESCC patients treated via definitive CRT or definitive CRT $(p<0.001)(B)$ Kaplan-Meier survival curves for clinical stage I patients stratified based on treatment modality $(p=0.0343)$. (C) Kaplan-Meier survival curves for Clinical stage II patients stratified based on treatment modality $(p<0.001)$. (D) Kaplan-Meier survival curves for Clinical stage III patients stratified based on treatment modality $(p<0.001)$. 

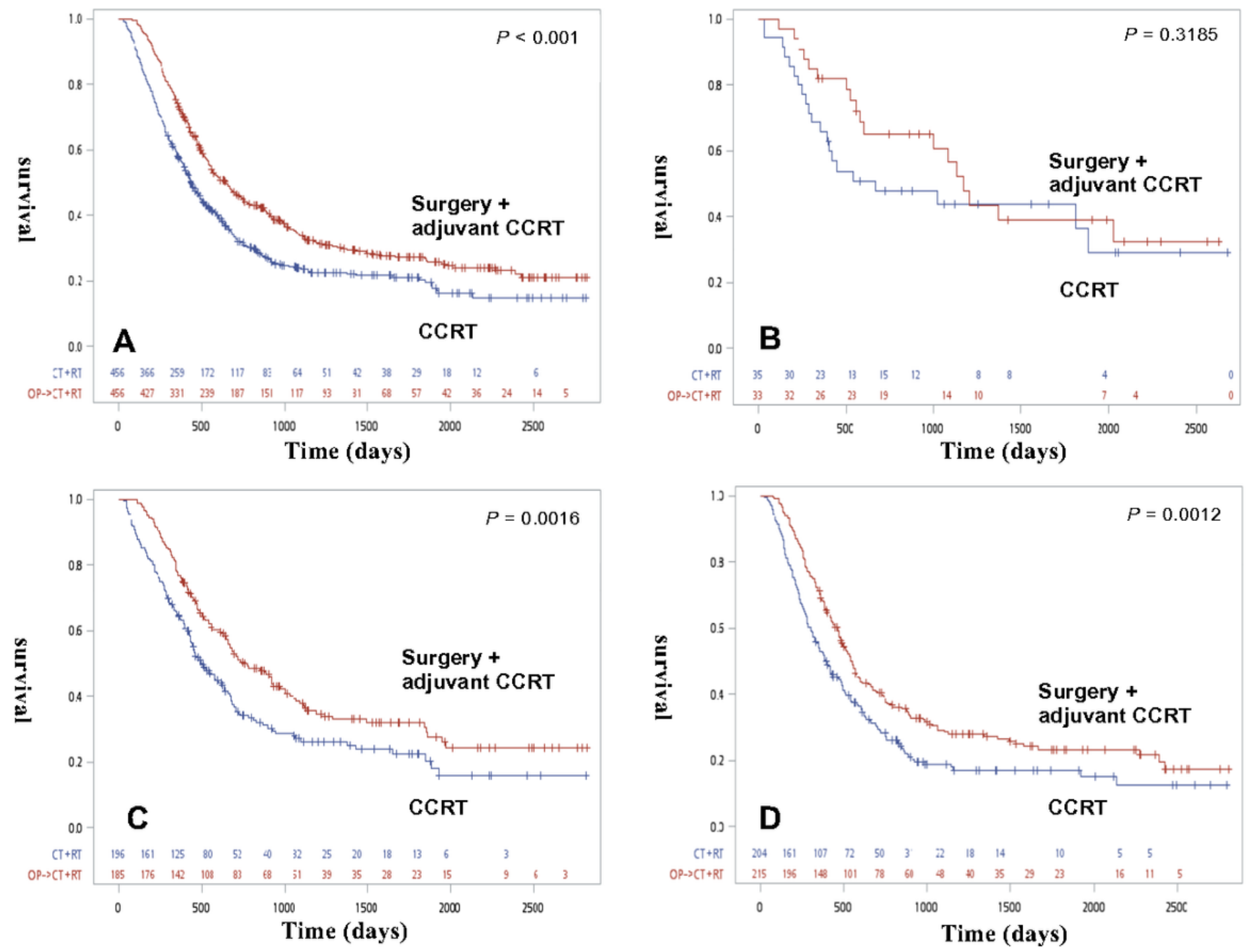

Figure 2

(A) Kaplan-Meier survival curves for ESCC patients receiving definitive CRT or definitive CRT after propensity matching. $(p<0.001)$.(B) Kaplan-Meier survival curves for clinical stage I patients stratified based on treatment modality after propensity matching. $(p=0.3185)$. (C) Kaplan-Meier survival curves for clinical stage II patients stratified based on treatment modality after propensity matching $(p=0.0016)$. (D) Kaplan-Meier survival curves for clinical stage III patients stratified based on treatment modality after propensity matching. $(p=0.0012)$. 